\title{
Offshoring and Manufacturing Employment: A General Equilibrium Analysis
}

\author{
Cosimo Beverelli \\ Graduate Institute of International Studies
}

\begin{abstract}
We study the incidence of offshoring, or trade in tasks, on firms' productivity and on manufacturing employment in a standard economic-geography model with iceberg trade costs and a continuum of tasks. In a two-countries world where one country has a Hick's neutral technological edge over the other, tasks in which the productivity edge more than offsets offshoring costs get offshored, giving rise to global disintegration of the production process. Offshoring raises firms' productivity and the number of manufacturing firms in the offshoring countries, thereby reducing costs of living. The general equilibrium incidence of offshoring on labor demand is shown to depend on offshoring costs and trade costs. For high enough offshoring costs, interior equilibria where both countries still produce manufactured goods are likely to be sustained. In this case, offshoring will boost labor demand for low enough trade costs. If, on the other hand, offshoring costs are low enough, core-periphery equilibria with all manufacturing in the offshoring country are likely to emerge. In this case, manufacturing labor demand is positively affected by offshoring as long as offshoring costs are not too low. In a threecountries extension, we show that a country would suffer welfare and employment losses from the adoption of policies that limit its firms' possibility to go offshore while similar countries allow offshoring.
\end{abstract}

(C) The Authors.

All rights reserved. No part of this paper may be reproduced without the permission of the authors. 


\title{
Offshoring and Manufacturing Employment: A General Equilibrium Analysis
}

\author{
Cosimo Beverelli*
}

October, 2007

\begin{abstract}
We study the incidence of offshoring, or trade in tasks, on firms' productivity and on manufacturing employment in a standard economicgeography model with iceberg trade costs and a continuum of tasks. In a two-countries world where one country has a Hick's neutral technological edge over the other, tasks in which the productivity edge more than offsets offshoring costs get offshored, giving rise to global disintegration of the production process. Offshoring raises firms' productivity and the number of manufacturing firms in the offshoring countries, thereby reducing costs of living. The general equilibrium incidence of offshoring on labor demand is shown to depend on offshoring costs and trade costs. For high enough offshoring costs, interior equilibria where both countries still produce manufactured goods are likely to be sustained. In this case, offshoring will boost labor demand for low enough trade costs. If, on the other hand, offshoring costs are low enough, core-periphery equilibria with all manufacturing in the offshoring country are likely to emerge. In this case, manufacturing labor demand is positively affected by offshoring as long as offshoring costs are not too low. In a three-countries extension, we show that a country would suffer welfare and employment losses from the adoption of policies that limit its firms' possibility to go offshore while similar countries allow offshoring.
\end{abstract}

Keywords: Trade in tasks, employment, productivity.

JEL Classification: F12, F16, F29

\footnotetext{
${ }^{*}$ Graduate Institute of International Studies, 11a, Avenue de la Paix, 1202 Geneva, Switzerland; e-mail: beverel1@hei.unige.ch. I thank Richard Baldwin for invaluable guidance, Marco Fugazza and Pamela Bombarda for useful discussions. The usual disclaimer applies.
} 


\section{Introduction}

The advances in information and communication technologies over the past decade have virtually ended the need to undertake manufacturing stages near each other. This process has given rise to a rapid growth in trade in intermediate goods and offshoring.

Offshoring, or trade in tasks, refers to the possibility of unbundling the production process of goods or services by assigning tasks to individuals, or teams, in different global locations. The study of offshoring is then the study of how globalization affects individuals.

This paper models the general equilibrium effects of offshoring in a simple framework in which countries have access to different technologies and trade in goods is costly. The main focus of the analysis is manufacturing labor demand. This is an important issue in the policy debate about offshoring. The public in OECD nations is often faced with scary predictions about massive job losses, and is often led into the fallacious equation "number of jobs offshored equal to number of jobs lost in the economy".

In this paper we argue that offshoring can well be associated with job creation in the manufacturing sector, depending on the interaction of offshoring costs and trade costs.

As in recent theoretical contributions (Grossman and Rossi-Hansberg, 2006), we model offshoring as cost-saving for firms because they can combine cheap Foreign labor with superior technology to perform some routine tasks abroad. However, there are some costs associated with offshoring, which deteriorate the better technology when it is associated with foreign labor. As a consequence, only the tasks in which the wage gap more than offsets the offshoring costs get offshored, giving rise to global production disintegration.

Due to its cost-saving nature, offshoring has a direct competitiveness effect. In a simple two-nations setting, firms from the offshoring country gain market shares vis-à-vis firms from the recipient country. Two equilibria can then emerge, depending on the level of cost savings from offshoring. If cost savings are limited, the backward nation keeps producing some manufactured varieties. The resulting international division of labor is one in which both countries produce manufactured goods assembling the tasks performed in the backward nation and the non-offshored tasks. If cost savings are important, on the other hand, firms from the backward nation cannot stand competition from firms from the advanced nation. A core-periphery equilibrium emerges, with the backward nation performing routine tasks and the other producing all manufactured goods. 
The number of manufacturing firms increases in the offshoring nation due to the realization of cost-advantages. This is what Hijzen and Swamy (2007) call "scale effect" of offshoring. On the other hand, some routine tasks are now lost to the low-wage country, so that per-firm employment decreases (the "technology effect" of offshoring in Hijzen and Swamy, 2007).

Manufacturing labor demand in the offshoring nation is higher if the technology effects dominates the scale effect, lower otherwise.

In an interior equilibrium, the technology effect dominates (so that manufacturing employment increases under offshoring) if trade costs are not too high. This is because with low trade costs firms find it relatively more convenient to locate in the offshoring nation and export to the other nation. The offshoring nation would thus benefit, in terms of manufacturing employment, from trade liberalization even when some tasks are lost to low-wage nations.

In a core-periphery equilibrium, on the other hand, the outcome is only affected by offshoring costs, not trade costs. We derive the simple result that manufacturing employment is depressed only if offshoring costs are low enough, because in this case the set of offshored tasks is too large.

The direct competitiveness effects of offshoring have clear implications for international competition. Suppose two symmetric nations are engaged in intra-sectoral competition, and suppose offshoring to a third nation becomes viable. If any of the two symmetric nations forbids offshoring in an attempt to "save" jobs, it creates an externality that will put its own firms at a competitive disadvantage vis-à-vis foreign competitors (third-market competitiveness effect). Conversely, if a nation encourages offshoring, it can sustain high levels of manufacturing employment, as the experience of Japan clearly demonstrates: by the mid-1980s the phenomenal growth of Japanese incomes and wages had eroded Japan's comparative advantage in manufacturing. Japanese manufacturers reacted by offshoring labour-intensive production stages to nearby East Asian nations. The offshoring of some low-wage jobs made Japanese companies more competitive in the US and European markets and this helped maintain high-wages industrial jobs in Japan. Offshoring, in other words, was a source of Japan's comparative advantage in US and EU markets (see Baldwin, 2006b).

In a simple three-countries extension of the basic model with two rich nations and a poor nation, we show the pervasiveness of this result. Interestingly, we find that if the benefits of offshoring are high enough, the non-offshoring rich country risks to become part of the global periphery, with unambiguously adverse effects on the number of manufacturing jobs. 
The paper is organized as follows: in the next section, we review the recent theoretical and empirical literature on offshoring. We then present a simple two-country model to focus on the employment effects of offshoring in the manufacturing sector. In Section 5 we extend the model to three countries. Section 6 concludes and discusses some policy implications of our model.

\section{Literature review}

Here we briefly review the recent theoretical and empirical literature on the effects of offshoring.

\subsection{Theoretical literature}

The general equilibrium effects of offshoring are at the center of a growing theoretical literature. Baldwin (2006b) suggests that there are two main strands of this literature: the so-called "Mankiw offshoring" and the Grossman-Rossi Hansberg (GRH) offshoring.

Mankiw offshoring can be conceptualized as trade in intermediate goods and services based on comparative advantage. The focus is on sectors (or, at a finer level of disaggregation, goods). The main insight to be gained from this strand of literature is that offshoring is akin to technical progress: by allowing nations to specialize in the production of (intermediate) goods and services for which they enjoy comparative advantage, offshoring allows to produce more final goods with the same amount of primary factors (definition of productivity increase and thus of technical progress). As Mankiw puts it, "offshoring is just the latest manifestation of the gains from trade that economists have talked about at least since Adam Smith" (quoted by Friedman, 2006, p. 231). ${ }^{1}$ Despite the overall gains from offshoring, however, the general equilibrium effects on different skill groups is ambiguous, even holding constant terms-of-trade effects. These effects will generally depend upon which sector undertakes the offshoring and whether the offshoring is labor- or (human) capital-saving (Baldwin, 2006b).

GRH offshoring, on the other hand, works at a finer level of disaggregation, namely individual tasks. At the very bottom, GRH offshoring is best understood as the combination of the home nation's better technology and

\footnotetext{
${ }^{1}$ Sadly, this statement triggered numerous outraged reactions among some not-sotrained in economics American policy-makers. As reported by Friedman (2006), the winner was speaker of the house Dennis Hastert, who claimed that Mankiw's "theory fails a basic test of real economics".
} 
cheaper input costs in the performance of offshored tasks. ${ }^{2}$ In particular, when a task gets offshored in a low-wage country, it is performed using the superior technology of the high-wage country; however, there are some costs associated with offshoring, which deteriorate the better technology when it is associated with foreign labor. As a consequence, only the tasks in which the wage gap more than offsets the offshoring costs get offshored. In this framework, offshoring has a productivity effect that boosts the wage in the offshoring nation. ${ }^{3}$ The intuition is simple: since a worker's productivity is a weighted average of his productivity in each task he performs, and since with offshoring he performs only the subset of tasks in which he is more productive - when offshoring takes place the worker's average productivity will rise, and so will his wage, which is tied to productivity. ${ }^{4}$

The different levels of aggregations considered by these two approaches have dramatically different policy implications. Under Mankiw offshoring, as we have written, the focus is on sectors (or goods); under GRH offshoring, on the other hand, it is on individuals. With the former, globalization positively affects sectors of comparative advantage and hurts other sectors. With the latter, globalization positively affects individuals that are capable of ever increasing their productivity, working with new technology, being flexible and possibly participating to international teams. The impact of policies directed at "easening" the effects of globalization will crucially depend on whether the effects are sector- or individual-specific.

\subsection{Empirical literature}

We turn now to a brief review of the empirical literature on the productivity and labor market effects of offshoring. Most of the studies cited below use the definition of material offshoring proposed by Feenstra and Hanson (1996)

\footnotetext{
${ }^{2}$ In Mankiw offshoring, instead, each nation uses its own technology, and the patterns of specialization depend on whether the wage gap offsets the productivity gap (comparative advantage).

${ }^{3}$ Notice that GRH offshoring is akin to shadow migration, whereby workers from a low-wage nation migrate to a high-wage nation, use the latter's better technology but get paid the same wage as in the nation of origin.

${ }^{4}$ Another major result of GRH offshoring is the unambiguously positive general equilibrium incidence of offshoring labor-intensive tasks on the reward to labor (holding terms of trade constant). The intuition is that when offshoring of labor-intensive tasks occurs, it is done both by the labor-intensive and by the (human) capital-intensive sector.
} 
for any industry $j$ in a nation:

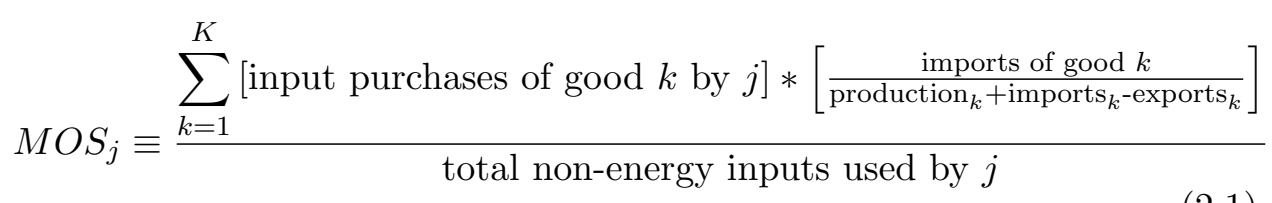

Feenstra and Hanson (1999) further propose to distinguish between a narrow and a broad concept of offshoring: the former accounting from input purchases only from the same industry; the latter accounting for input purchases from all other industries.

\subsubsection{Productivity effects}

Numerous studies have analyzed the effect of offshoring on productivity, at various levels of aggregation (a survey of this literature can be found in Olsen 2006). At an aggregated level, the most relevant studies are Egger and Hegger (2001) for the European Union and Amiti and Wei (2006) for the United States. The former analyze the impact of offshoring (measured using Feenstra and Hanson's narrow definition) on the productivity level of low-skilled workers using data on 22 manufacturing industries (2-digit NACE) in $12 \mathrm{EU}$ countries over the period 1992-97. They find a positive long-run impact, but (perhaps due to EU's generally inflexible labor markets) a negative shortrun impact. Amiti and Wei (2006) distinguish between material outsourcing and service offshoring (calculated as in (2.1), by substituting service input purchases for good input purchases). In a panel of 96 industries, they find that service offshoring has a positive effect on labor productivity (accounting for around 20 percent of the average growth in US labor productivity over the period 1992-2000) and material offshoring has also a positive but somehow smaller effect. A more pronounced productivity impact of material offshoring is found by Egger, Pfaffermayr, and Wolfmayr-Schnitzer (2001) for a small EU country, Austria, using data on 18 manufacturing industries (2-digit NACE) over 1990-1998.

At a more disaggregated level, numerous studies provide mild evidence of a positive productivity impact of service outsourcing at the plant level. Hijzen, Tomojiko, and Todo (2007), for example, using Japanese firm-level data for the period 1994-2000, find that offshoring (measured as the ratio of expenditure on subcontracting of products, parts and components to foreign providers to value added of the firm) has generally a positive effect on total factor productivity (TFP) growth. The scope of this effect however 
negatively depends on the initial level of productivity of the firm: firms with lower TFP benefit more from offshoring than firms with higher TFP.

\subsubsection{Labor demand effects}

Another set of papers have analyzed the impact of offshoring activities on labor markets (for extensive reviews, see Crinò, 2007 and Kirkegaard, 2007). The first strand of this literature - focused on service offshoring - has studied the issue is how many jobs can/will be offshored as a consequence of the increased tradability of services due to technological innovation. ${ }^{5}$ Van Welsum and Reif (2005) and Van Welsum and Vickory (2006) classify "offshorable" jobs as those characterized by four attributes:

- intensive use of ICTs (information and communication technologies)

- output that is ICT transmittable

- codifiable knowledge content

- little face-to-face interaction

They classify about $20 \%$ of the U.S. workforce as being offshorable. Blinder (2007) comes up with similar results, estimating that somewhere between $22 \%$ and $29 \%$ of all U.S. jobs are or will be potentially offshorable within a decade or two. The other prominent projections have been advanced by consulting firms. The dominant and most widely quoted projection of future job losses is Forrester Research's "3.3 Million US Services Jobs to Go Offshore" (McCarthy, 2002).

Although the numbers appear to be enormous, they are quite small in relative terms. In fact, they should be "compared to the more than 160 million jobs projected [...] to exist by 2015, and [...] to the 35 million new jobs gained over the past decade" (Mankiw and Swagel, 2006, p. 1042). Moreover, these estimates may be exaggerated. Whether a task is offshorable, in fact, crucially depends on the complex ways in which it is "bundled" together with other tasks. It is possible for some tasks that score high on the offshorability criteria spelled above to be effectively non-offhshorable, because it must be performed together with tasks that are non-offshorable.

\footnotetext{
${ }^{5}$ Although service offshoring is a hot topic in the current public debate (possibly because of fears of loss of white-collar jobs), it should be noted that it is yet a very limited phenomenon: Amiti and Wei (2006) find that the share of imported service inputs in the year 2000 for the U.S. was only 0.3 percent (whereas the share of imported material inputs was 17.4 percent).
} 
In this case, the researcher should take into account coordination costs in order to understand which tasks are effectively offshorable.

The second strand of this literature estimates empirically the effects of material and service offshoring on: how many jobs have actually been lost; wage inequality and relative employment across workers with different skills; elasticities of unskilled labor demand. The studies on material offshoring generally find a negative effect on the relative labor demand for workers with the lowest level of skill; however, the impact on the elasticity of unskilled labor demand and on the risk of job losses is small (Crinò, 2007, p. 37). In their study of 89 Swedish industries in the period 1995-2000, Ekholm and Hakkala (2005) distinguish between offshoring to low-income countries and offshoring to high-income countries. The former reduces demand for workers with an intermediate level of education, while exerting positive effects on the relative demand for workers with higher educational attainments. The latter (the main type in Sweden's case) has no statistically significant effect. Hijzen and Swamy (2007) analyze the effects of material offshoring on industry employment using industry-level data for 17 high income OECD countries. They draw a distinction between technology and scale effects of offshoring. As discussed in Section 1, the former reflects the destruction of jobs occurring when firms relocate part of their production activities abroad. The latter refers to the creation of new jobs following the expansion in industry output as a result of productivity gains from offshoring. Since the two effects pull in different directions, the total effect of offshoring is ambiguous. The authors estimate a conditional an unconditional labor demand equation, alternatively using inter-industry and intra-industry offshoring (respectively, broad and narrow offshoring in Feenstra and Hanson, 1999) as explanatory variable. Offshoring has a negative impact on employment in the conditional model, but no effect in the unconditional one. As the authors argue, "the difference between the conditional and unconditional estimates is consistent with the productivity gains from intra-industry offshoring being sufficiently large for the jobs created by higher sales to completely offset the jobs lost by relocating certain production stages to foreign production sites. Similarly, inter-industry offshoring [...] is found to increase industry-level labour demand" (Hijzen and Swamy, 2007, p. 11).

Turning to service offshoring, the empirical literature has found at most very limited negative effects on total employment, demonstrating that the widespread media concern (most certainly fueled by some of the estimations mentioned early) over the job losses following service outsourcing is misguided. Amiti and Wei (2006), for example, find a positive employment of 
service outsourcing both at the more aggregated level (96 industries in the U.S.) and at the more disaggregated level (450 industries in the U.S.). The same authors obtain similar results when studying manufacturing industries in the U.K.: service offshoring has no negative effect on labor demand, and even a positive effect in some specifications (Amiti and Wei, 2005).

Overall, the empirical literature does not find convincing evidence of negative employment effects of offshoring - be it in services or in physical intermediate inputs. On the contrary, there is some evidence pointing in the opposite direction, consistent with the theoretical findings of this paper.

\section{A Two-Countries Model}

Consider a world of two countries, Home and Foreign (indicated with a star). Their respective economy is composed of two sectors, $A$ and $M$. Sector $A$ is marked by perfect competition, constant returns to scale and it produces an homogenous good. The $M$ sector produces imperfectly substitutable varieties under monopolistic competition and increasing returns to scale. The homogenous sector- $A$ good is freely traded internationally. Trade in $M$, on the other hand, is subject to the standard Samuelson iceberg trade costs; specifically, a fraction $1 / \tau$ of exports melt in transit. There is one factor of production, labor $(L)$, which is supplied inelastically and is mobile across sectors within each nation, so that the wage rate prevailing in each nation is unique. Home and Foreign are respectively endowed with $L\left(L^{*}\right)$ units of labor.

Rule out the possibility of offshoring tasks for the time being. We assume that the Home country's technology in both sectors is a Hicks-neutral improvement upon Foreign's technology: specifically, denoting $a_{k}$ as the unit labor requirement to produce one unit of good $k, k \in(A, M)$, at Home and $a_{k}^{*}$ as the unit labor requirement in Foreign, we let:

$$
a_{k}^{*}=\delta a_{k} \quad \delta>1
$$

( $\delta$ is a mnemonic for technological distance).

Turning to consumer preferences, they are represented by a Cobb-Douglas utility function of the form:

$$
U=A^{1-\mu} M^{\mu} \quad M \equiv\left(\int c_{i}^{1-1 / \sigma} d_{i}\right)^{\frac{1}{1-1 / \sigma}}
$$

where $\mu$ is the share of income spent on the Dixit-Stiglitz-Spence CES aggregate of varieties $M$. 
Technology in the $A$ sector is simple: in order to produce a unit of $A$ at Home (Foreign), $a_{A}\left(a_{A}^{*}\right)$ units of labor are needed. Since $A$ is marked by constant returns to scale and perfect competition, it is a natural numéraire. Then by free trade and choosing units of $A$ such that $a_{A}=1$, we get:

$$
w=1 \quad w^{*}=1 / \delta
$$

In words, the model yields effective factor price equalization (the productivityadjusted wage rate is equalized across countries).

The characterization of firm's technology in the $M$ sector is also simple: each firm active in the $M$-sector needs $a_{M}$ units of labor to produce each unit of output plus $F\left(F^{*}\right)$ units of labor as a start-up cost; the cost function is thus homothetic. We assume that the ratio of Foreign to Home fixed costs is equal to the productivity gap $\delta$, viz., $F^{*}=\delta F$. This implies that the cost structure of a typical Home firm is exactly equal to the cost structure of the typical Foreign firm, because the productivity advantage $(\delta)$ is exactly offset by the wage differential $(\delta)$ both in the variable component and in the fixed component of the cost structure:

$$
\begin{aligned}
T C & \equiv\left(a_{M} x+F\right) w \\
T C^{*} & \equiv\left(a_{M}^{*} x^{*}+F^{*}\right) w^{*}=T C
\end{aligned}
$$

where we have used $x=x^{*}$ (we will see below that this condition holds). For notational simplicity, we drop the index " $M$ " from the input requirement coefficients: we shall thus define $a_{M} \equiv a ; a_{M}^{*} \equiv a^{*}=\delta a$.

As it is well-known in monopolistic competition, profit-maximizing firms chose production prices as a fixed mark-up over marginal costs:

$$
p_{M}=\frac{w a}{1-1 / \sigma} \quad p_{M}^{*}=\frac{w^{*} a^{*}}{1-1 / \sigma}
$$

Choosing units of $M$ such that $a=1-1 / \sigma$, we have $p_{M}=w=p_{M}^{*}$. Since Home and Foreign firms have the same cost function, they charge the same producer price.

\subsection{Initial Equilibrium}

In this model, the following expressions for operating profits hold:

$$
\pi=\frac{\mu}{\sigma}\left(\frac{E}{\Delta}+\phi \frac{E^{*}}{\Delta^{*}}\right) \quad \pi^{*}=\frac{\mu}{\sigma}\left(\phi \frac{E}{\Delta}+\frac{E^{*}}{\Delta^{*}}\right)
$$


where

$$
\Delta=n+\phi n^{*} \quad \Delta^{*}=\phi n+n^{*}
$$

In these expressions, $\mu E\left(\mu E^{*}\right)$ is Home (Foreign) expenditure across varieties, ${ }^{6} n\left(n^{*}\right)$ is the number of Home (Foreign) varieties, and $0<\phi \equiv$ $\tau^{1-\sigma}<1$ represents "freeness" of trade (the closer to one, the lower trade costs).

Next, impose free entry: at equilibrium, firms make zero pure profit, yielding $\pi=F w\left(\pi^{*}=F^{*} w^{*}\right)$. Normalizing $F=1 / \sigma$, the equilibrium number of varieties produced at Home an in Foreign as a function of size is given by:

$$
n=\frac{\mu}{1-\phi}\left(E-\phi E^{*}\right) \quad n^{*}=\frac{\mu}{1-\phi}\left(E^{*}-\phi E\right)
$$

This model exhibits a standard home-market effect (HME) and HME magnification (Krugman, 1980): $s_{N}=\frac{1}{2}+\frac{1+\phi}{1-\phi}\left(s_{E}-\frac{1}{2}\right.$ ), where $s_{N} \equiv \frac{n}{n+n^{*}}$ is the share of Northern varieties and $s_{E} \equiv \frac{E}{E+E^{*}}$ is the share of Northern consumption (i.e., Northern relative market size).

Since there are no pure profits in the economy, overall expenditure is equal to the labor income:

$$
E=w L=L \quad E^{*}=w^{*} L^{*}=L^{*} / \delta
$$

We can thus express $n$ and $n^{*}$ as a function of size (respectively, $L$ and $L^{*}$ ):

$$
n=\frac{\mu}{1-\phi}\left(L-\phi \frac{L^{*}}{\delta}\right) \quad n^{*}=\frac{\mu}{1-\phi}\left(\frac{L^{*}}{\delta}-\phi L\right)
$$

The model yields corner solutions for high enough values of trade freeness. Following standard notation in the economic geography literature, we denote the threshold level of trade freeness below which all manufacturing activities are located at Home as $\phi^{S}$ ( $\phi$ sustain). It is easy to see that $\phi^{S}$ is equal to the effective size ratio of the two countries, $\phi^{S}=\rho \equiv \frac{L^{*} / \delta}{L}$.

Clearly, $\phi^{S}$ is equal to one only if the two countries have equal effective size. If Foreign is smaller in effective units, for high enough levels of $\phi$ we hit a core-periphery outcome at Home. We assume that $\rho \leq 1$ to rule out the possibility of core-periphery in Foreign.

We can now characterize welfare: Home (Foreign) welfare in this model

\footnotetext{
${ }^{6}$ Due to the Cobb-Douglas specification of consumer's preferences, each consumer allocates a fraction $\mu$ of his income on $M$ goods and a fraction $1-\mu$ on the homogenous good.
} 
is equal to $E / P\left(E^{*} / P^{*}\right)$ where $P\left(P^{*}\right)$ is the price index: $P=\Delta^{\frac{\mu}{1-\sigma}}$ $\left(P^{*}=\left(\Delta^{*}\right)^{\frac{\mu}{1-\sigma}}\right)$. Using the above results, Home and Foreign welfare can be expressed as a function of the respective market size and parameters:

$$
W=(L)^{\gamma}[\mu(1+\phi)]^{\frac{\mu}{\sigma-1}} \quad W^{*}=\left(\frac{L^{*}}{\delta}\right)^{\gamma}[\mu(1+\phi)]^{\frac{\mu}{\sigma-1}}
$$

where $\gamma \equiv \frac{\sigma-(1-\mu)}{\sigma-1}>1$. Notice that Home welfare is unaffected by the technological gap $\delta$, whereas Foreign welfare negatively depends on $\delta$.

It is useful to construct, as benchmark case, a symmetric equilibrium: consider equal effective size: $L=L^{*} / \delta(\rho=1)$; then:

$$
n^{s}=\left(n^{*}\right)^{s}=\mu L \quad W^{s}=\left(W^{*}\right)^{s}=W
$$

where the superscript " $s$ " stands for symmetry.

\subsection{Offshoring equilibrium}

In order to introduce offshoring, assume now that $a$ involves a continuum of tasks (of mass one) involving labor only, each of them denoted by $j$ and each of them equally needed. Thus,

$$
a=\int_{0}^{1} a(j) d(j)
$$

Next, assume that tasks can be offshored at a cost. Specifically, it costs the equivalent of $\beta \tau(j)$ hours of work on task $j$ to get a worth of one hour of work when task $j$ is offshored $(\beta \tau(j) \geq 1)$. Following GRH, we assume that $\tau(\cdot)$ is continuously differentiable and we order tasks so that the costs of offshoring are non decreasing: $\tau^{\prime}(j) \geq 0$. Crucially, as in GRH, a domestic firm gets to use Home technology in the Foreign nation when it offshores a task to Foreign. Thus, the decision to offshore a particular task $j$ will revolve around the inequality:

$$
w a_{M}(j)>\beta \tau(j) w^{*} a_{M}(j) \Leftrightarrow \delta>\beta \tau(j)
$$

This intuitive expression tells that it is worth offshoring a task if the technological gap is bigger than the offshoring cost. ${ }^{7}$ Consequently, Home firms will offshore a set of tasks $\Theta(\beta, \delta)$ such that:

$$
\Theta(\beta, \delta)=\{j: \beta \tau(j) \leq \delta\}
$$

\footnotetext{
${ }^{7}$ Notice that Foreign firms will not find it convenient to offshore at Home, because the would combine their inferior technology with higher Home wages.
} 
The offshoring cut-off condition (when this expression holds with equality) implicitly defines the threshold task $T_{O}$ :

$$
T_{O}=\tau^{-1}\left(\frac{\delta}{\beta}\right)
$$

Clearly, using (3.3), it is immediate to see that the possibility of going offshore reduces production costs ("offshoring production effect"):

$$
a>a^{O} \equiv \int_{j \notin \Theta(\delta)} a(j) d(j)+\int_{j \in \Theta(\delta)} \frac{\beta \tau(j)}{\delta} a(j) d(j)
$$

where $a^{O}$ represents the unit labor requirement under offshoring and $w^{O}$ is the average wage (including offshoring costs on tasks in the set $\Theta(\beta, \delta)$ ) paid by Home producers (the superscript " $O$ " stands for offshoring). Note that $a^{O}$ is decreasing in $\delta$ for two reasons. First, the larger the technological gap, the larger the benefits of offshoring the tasks in $\Theta(\delta)$ (recall that Home firms use the superior technology when offshoring); in addition, the set of offshored tasks $\Theta(\beta, \delta)$ expands. ${ }^{8}$

The expression for the wage paid by offshoring firms is:

$$
w^{O} \equiv w\left[\int_{j \notin \Theta(w)} d(j)+\int_{j \in \Theta(w)} \frac{\beta \tau(j)}{\delta} d(j)\right]
$$

which is a weighted average between the wage paid to workers performing tasks at Home and the wage paid to workers performing tasks at Foreign. Notice that $w^{O}<w$ : firms face lower wages on average under offshoring.

\subsubsection{Functional forms}

Let $\tau(j)$ be a simple linear function, $\tau(j)=j, j \in[0,1]$. Low-end tasks (form zero up to the threshold task) will be offshored, high-end tasks (from the threshold task to one) will not. Next, assume that the same labor input is used to perform each $j$ task, viz. $a(j)=a \forall j$. Recall that Home technology is a Hick's neutral improvement upon Foreign's. Under this assumption, this is not only the case across sectors, but also across tasks within the $M$ sector; in symbols, $a_{0}^{*}=\delta a_{0}, \ldots, a_{j}^{*}=\delta a_{j}, \ldots, a_{1}^{*}=\delta a_{1}$. Home has thus

\footnotetext{
${ }^{8}$ In this simple setting, $a^{O}$ is equal to the marginal cost of the typical offshoring firm: $w a^{O}=w^{O} a \equiv m c^{O}=a^{O}$ (using the normalization $w=1$ ).
} 
an absolute advantage in all tasks, but a comparative advantage in any of them. For this reason, offshoring cannot be of the Mankiw-type (i.e., based on different comparative advantage in tasks), but only of the GRH type.

From (3.4), the threshold task $T_{O}$ is simply equal to $\delta / \beta$, which is trivially decreasing in $\beta$ : a reduction of offshoring costs increases the range of offshored tasks. Because tasks are ordered on the $[0,1]$ interval, an interior equilibrium where $T_{O}$ belongs to this interval, and consequently both nations perform some tasks, will be found by imposing the condition $\beta>\delta .{ }^{9}$

The variable component of the wage bill (marginal costs) under offshoring can then be computed from (3.5), and it is equal to:

$$
m c^{O}=m c\left[1-\frac{1}{2}\left(\frac{\delta}{\beta}\right)\right]
$$

where $m c=w a=1-1 / \sigma$ is the marginal cost in the absence of offshoring. Clearly, the quantity in square brackets in this expression is equal to the price charged by firms under offshoring:

$$
p^{O}=1-\frac{1}{2}\left(\frac{\delta}{\beta}\right)
$$

This expression makes clear that $p^{O}$ is increasing in offshoring costs $\beta$. By the assumption $\beta>\delta$, we have that $1 / 2<p^{O}<1$ : as explained before, offshoring reduces production costs and thus the price firms can charge. Notice that from (3.6) we can compute $w^{O}=1-\frac{1}{2}\left(\frac{\delta}{\beta}\right)=p^{O}$.

\subsection{Production and welfare under offshoring}

We have seen that offshoring changes the cost structure of Home firms, that can use the better technology and take advantage of lower labor costs. Assume that Foreign firms' cost structure is unaffected by offshoring (i.e., they do not gain access to Home technology, even when some tasks get offshored). ${ }^{10}$ We expect the offshoring-linked shift in Home versus Foreign firms'competitiveness to affect the location of firms. In other words, offshoring becomes a source of comparative advantage.

To see this, assume we start from a full symmetric equilibrium where $n=$

\footnotetext{
${ }^{9}$ We may justify this assumption with political economy arguments: it may not be politically feasible to offshore the entire set of tasks needed to produce manufactured goods.

${ }^{10}$ For a similar assumption, see Baldwin and Robert-Nicoud (2007).
} 
$n^{*}=\mu L$ (equation (3.1)). A reduction in $\beta$ makes it possible for Home firms to offshore some tasks in Foreign. Home firms will become more productive and will be able to charge a lower price $\left(p^{O}<p\right)$, winning a competitive edge over Foreign firms, whose cost structure is left unchanged. More firms will entry at Home, while some firms will shut down in Foreign. As offshoring costs decrease, the number of Home firms will increase and the number of Foreign firms will decrease, making Home a net exporter of manufactured goods.

It should be clear that for sufficiently low offshoring costs, the competitive disadvantage of Foreign firms will become too high, and no manufacturing firms will be left in Foreign. In other words, we will hit a core-periphery equilibrium with core at Home. We shall define the minimum level of offshoring costs such that both countries produced manufactured goods as $\beta^{S}$ (sustain point).

Two cases need to be distinguished: the interior equilibrium (IE) where $\beta>\beta^{S}$ and $n^{*}>0$, and the core-periphery equilibrium (CP) where $\beta<\beta^{S}$ and $n^{*}=0$.

\section{Case 1 Interior equilibrium}

The free-entry conditions of the Dixit-Stiglitz demand system in an interior equilibrium are as follows:

$$
\begin{aligned}
\pi^{O} & =\frac{\mu}{\sigma}\left(\frac{\left(p^{O}\right)^{1-\sigma} E}{\Delta^{O}}+\phi \frac{\left(p^{O}\right)^{1-\sigma} E^{*}}{\left(\Delta^{*}\right)^{O}}\right)=\frac{1}{\sigma} \\
\pi^{*} & =\frac{\mu}{\sigma}\left(\phi \frac{E}{\Delta^{O}}+\frac{E^{*}}{\left(\Delta^{*}\right)^{O}}\right)=\frac{1}{\sigma}
\end{aligned}
$$

where

$$
\Delta^{O}=n^{O}\left(p^{O}\right)^{1-\sigma}+\phi\left(n^{*}\right)^{O} \quad\left(\Delta^{*}\right)^{O}=\phi n^{O}\left(p^{O}\right)^{1-\sigma}+\left(n^{*}\right)^{O}
$$

and the market size conditions are the same as in (3.1). Solving the system of free-entry conditions under offshoring, we can get $n^{O},\left(n^{*}\right)^{O}, W^{O},\left(W^{*}\right)^{O}$ as a function of size $\left(L, L^{*}\right)$, offshoring costs and parameters. In order to minimize the burden of notation, we express the solutions in terms of the 
collection of parameters $p^{O}$ defined in equation (3.7):

$$
\begin{aligned}
n^{O} & =\frac{\mu}{1-\phi}\left(\Phi_{1} L-\Phi_{2} \phi \frac{L^{*}}{\delta}\right) \frac{1}{\Phi_{3}} \\
n^{* O} & =\frac{\mu}{1-\phi}\left(\Phi_{4} \frac{L^{*}}{\delta}-\Phi_{5} \phi L\right) \frac{1}{\Phi_{3}} \\
W^{O} & =W\left(\frac{\Phi_{5}}{\Phi_{3}}\right)^{\frac{\mu}{\sigma-1}} \\
W^{* O} & =W^{*}\left(\frac{\Phi_{4}}{\Phi_{3}}\right)^{\frac{\mu}{\sigma-1}}
\end{aligned}
$$

where $\Phi_{1} \equiv 1-\phi\left(p^{O}\right)^{\sigma-1} ; \Phi_{2} \equiv\left(p^{O}\right)^{\sigma-1}-\phi ; \Phi_{3} \equiv \frac{\left(1+\phi^{2}\right)-\phi\left[\left(p^{O}\right)^{\sigma-1}+\left(p^{O}\right)^{1-\sigma}\right]}{1-\phi}$; $\Phi_{4} \equiv 1-\phi\left(p^{O}\right)^{1-\sigma} ; \Phi_{5} \equiv\left(p^{O}\right)^{1-\sigma}-\phi$.

It is easy to check that the situation without offshoring is just a particular case of this one, arising when $p^{O}=p=1$ (prohibitive offshoring costs, $\beta \rightarrow \infty)$.

Recall that this equilibrium is sustained only for high enough levels of offshoring costs, which correspond to high enough levels of $p^{O}$. The minimal level of $p^{O}$ such that the interior equilibrium computed above can be sustained, defined $\left(p^{O}\right)^{S}$, can be found from (3.8) to be equal to $\left[\frac{\phi(1+\rho)}{\rho+\phi^{2}}\right]^{\frac{1}{\sigma-1}}$. Using (3.7), we then find the sustain point of offshoring costs:

$$
\beta^{S}=\frac{1}{2} \frac{\delta}{1-\left[\frac{\phi(1+\rho)}{\rho+\phi^{2}}\right]^{\frac{1}{\sigma-1}}}
$$

This expression reveals that $\beta^{S}$ is increasing in $\phi$ : if trade freeness is high, a core-periphery outcome is hit with relatively high levels of offshoring costs. If trade freeness is low, on the other hand, the interior equilibrium find above is sustainable for a bigger range of offshoring costs.

\section{Case 2 Core-periphery equilibrium}

When offshoring costs are low enough, i.e., $\beta<\beta^{S}$, the number of foreign firms drops to zero. In this case, only the free-entry condition for Home firms holds, hence we impose $n^{*}=0$ in the expressions for $\Delta^{O}$ and $\Delta^{* O}$ and 
solve for the free-entry condition for Home firms to get:

$$
\begin{aligned}
n^{O} & =\mu\left(L+\frac{L^{*}}{\delta}\right) \\
n^{* O} & =0 \\
W^{O} & =L\left[\frac{\mu}{\delta}\left(p^{O}\right)^{1-\sigma}\left(L \delta+L^{*}\right)\right]^{\frac{\mu}{\sigma-1}} \\
W^{* O} & =\left(\frac{L^{*}}{\delta}\right)\left[\phi \frac{\mu}{\delta}\left(p^{O}\right)^{1-\sigma}\left(L \delta+L^{*}\right)\right]^{\frac{\mu}{\sigma-1}}
\end{aligned}
$$

Notice that $n^{O}$ is independent of $p^{O}$ (and thus of $\beta$ ): any further reduction in offshoring costs below the level that causes a core-periphery outcome will not affect the number of Home firms.

\subsection{Discussion}

The results of this Section are graphically represented in Figure 1. In order to ease interpretation, we plot the solutions obtained in the two cases as a function of an inverse measure of offshoring costs, $1 / \beta$. Since $\beta \in[\delta, \infty), 1 / \beta$ is bounded between 0 (with prohibitive offshoring costs, $\beta \rightarrow \infty$ ) and $1 / \delta$ (when offshoring costs are the lowest, $\beta \rightarrow \delta$ ). The vertical line represents the sustain point of $1 / \beta$, defined as $1 / \beta^{S}$.

Figure 1: Number of firms under offshoring

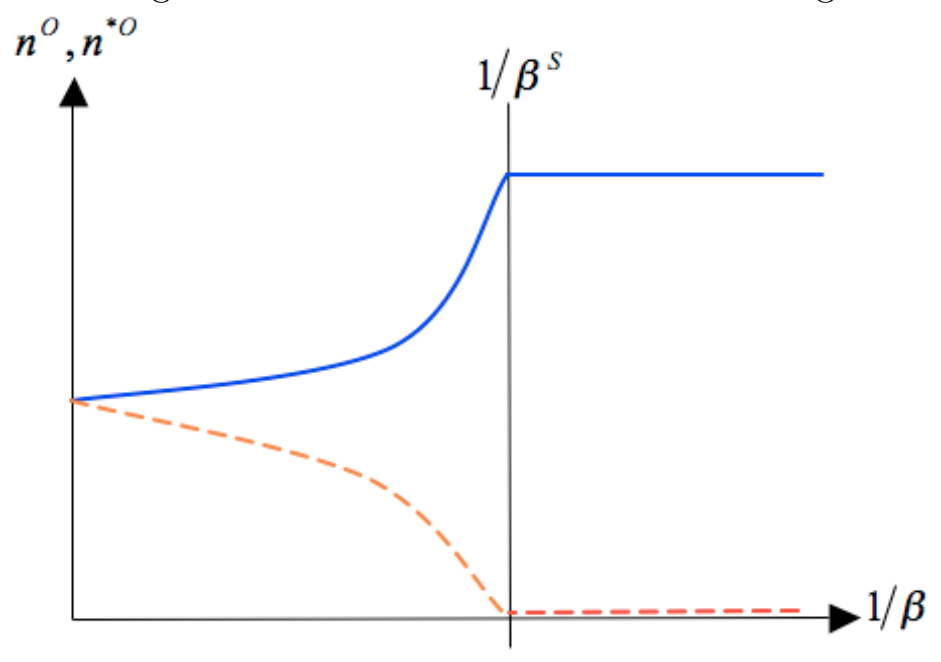

To the left of the sustain point, offshoring costs are high enough to allow both countries to produce manufactured goods; however, the competitive 
edge gained by Home firms through offshoring makes the number of Home firms increase, and the number of Foreign firms decrease, as offshoring costs decrease. When offshoring costs are lower than the sustain point, a coreperiphery equilibrium emerges. Hence:

Result 1. Offshoring changes the location of firms and the patterns of comparative advantage. The offshoring nation becomes a net exporter of manufactured goods.

The location effects described so far have important welfare implications. Consider the case of equal effective size, $\rho=1$. As we have seen above, in the absence of offshoring, the two nations enjoy the same level of welfare. What happens when Home firms gain the possibility to offshore tasks abroad? The relative welfare of the two nations can be expressed as:

$$
\begin{array}{lll}
\frac{W^{O}}{W^{* O}}=\left(\frac{\Phi_{5}}{\Phi_{4}}\right)^{\frac{\mu}{\sigma-1}}>1 & & \text { in IE } \\
\frac{W^{O}}{W^{* O}}=\phi^{\frac{\mu}{\sigma-1}}>1 & & \text { in } \mathrm{CP}
\end{array}
$$

Hence:

Result 2. Offshoring makes the world income distribution more uneven, by driving a wedge between the income of the offshoring nation and the income of the recipient nation.

The intuition for this result is clear: Given trade costs, Foreign consumers pay a higher price for the varieties that are imported, and consequently the price index abroad is higher than the domestic price index.

At this point, it should be made clear that the core at Home may well be associated with little manufacturing production at Home: recall that the threshold task $T_{O}$ is equal to $\delta / \beta$. For given $\delta$, as offshoring costs decrease, more and more tasks are undertaken in Foreign, even in situations where Foreign has no firms. A numerical example may best serve understanding: take $\rho=1 ; \phi=1 / 10 ; \sigma=4$. By equations (3.7) and (3.9), there is a coreperiphery in the model for any $p^{O}<0.58$. Assume that $p^{O}=0.55$ (very low offshoring costs): then only $10 \%$ of tasks will be conducted at Home and $90 \%$ abroad, although Foreign has no firms. Under the same parametric configuration but a more realistic level of trade freeness, $\phi=1 / 4$, the coreperiphery outcome would be hit for $p^{O}<0.78$. Consider then $p^{O}=0.75$ (higher offshoring costs). In this case, the threshold task $T_{O}$ is equal to $1 / 2$, 
arguably a considerable amount of tasks!

This brings us to the core question of the paper: what happens to the total number of manufacturing jobs at Home after offshoring.

\section{Offshoring and manufacturing employment}

In Sections 1 and 2 we discussed how the impact of offshoring on labor demand in manufacturing is central in the debate about offshoring. Bearing in mind the limitations of this model - which has only one factor of production and cannot address the important issue of how offshoring affects different skill groups - we can provide a simple analysis of the general equilibrium effects on the demand for labor.

Let's start with the model without offshoring. As it is well known, manufacturing labor demand can be derived from the cost function ( $T C=$ $(a x+F) w)$ using the Shepard's lemma. In order to ease comparison with the case of offshoring, we express $a=\int_{0}^{1} a_{M}(j) d(j)$, noting that when tasks are bundled together (no offshoring) the continuum of tasks is subsumed under the technology factor $a$. The calculation is simple:

$$
L_{M}=n \frac{\partial T C(w)}{\partial w}=n\left[\left(\int_{0}^{1} a(j) d(j)\right) x+F\right]
$$

In the free-entry equilibrium computed above, it can easily be shown that: ${ }^{11}$

$$
L_{M}=\lambda n \quad \lambda=1
$$

where $\lambda$ represents employment per firm (the reason why we use $\lambda$ will be clear in a few lines).

In order to see how manufacturing labor demand changes under offshoring, start with the new expression for total costs:

$$
T C^{O}=\left[\int_{j \notin \Theta(w)} w a(j) d(j)+\int_{j \in \Theta(\delta)} w^{*} \beta \tau(j) a(j) d(j)\right] x^{O}+F w
$$

\footnotetext{
${ }^{11}$ The free entry condition $(\pi=p x-T C=0)$ pins down firm output $x=\sigma F=1$ (equilibrium firm size is invariant to country size and trade costs). Substituting this result in the expression for manufacturing labor demand, together with the solution for $n$ and the usual normalizations, gives $L_{M}=n$.
} 
By Shepard's lemma, manufacturing labor demand under offshoring is equal to:

$$
L_{M}^{O}=n^{O} \frac{\partial T C^{O}}{\partial w}=n^{O}\left[\left(\int_{j \notin \Theta(w)} a(j) d(j)\right) x^{O}+F\right]
$$

Solving the free-entry condition $\pi^{O}=p^{O} x^{O}-T C^{O}=0$ (and using $p^{O}=$ $w^{O}$ ), we can pin down the scale of operation under offshoring:

$$
x^{O}=\frac{2 \beta}{2 \beta-\delta}
$$

Notice that $x^{O}>x=1$, that is:

Result 3. Firms' output is higher under offshoring. Intuitively, as marginal costs get lower, firms get bigger and sell more output.

Substituting equation (4.1) back into the expression for $L_{M}^{O}$, we then find:

$$
L_{M}^{O}=\lambda^{O} n^{O} \quad \lambda^{O} \equiv \frac{2 \sigma(\beta-\delta)+\delta}{(2 \beta-\delta) \sigma} \in(0,1)
$$

Notice that $\lambda^{O}$ is increasing in offshoring costs $\beta$. Moreover, $\lambda^{O}<\lambda$ :

Result 4. Offshoring reduces employment per firm.

The overall change in manufacturing employment depends on the relative impact of employment per firm effect versus the number of firms effect.

We can construct a function representing the loss of manufacturing jobs at Home after offshoring:

$$
\Lambda \equiv \frac{L_{M}}{L_{M}^{O}}=\frac{\lambda}{\lambda^{O}} \frac{n}{n^{O}}
$$

( $\Lambda$ is a mnemonic for 'loss'). The analysis will proceed as follows. We distinguish between the two cases, respectively interior and core-periphery equilibrium; in each case, we study the conditions under which $\Lambda \leq 1$, which is a necessary condition under which no manufacturing jobs are lost (or jobs are even created) at Home after offshoring. 


\section{Case 1 Interior equilibrium}

The expression for $\Lambda$ (conveniently written as a function of $p^{O}$ ) is found by substituting equation (3.8) in (4.2) above to get:

$$
\Lambda=\frac{(1-\rho \phi) \sigma p^{O}}{1-p^{O}+\sigma\left(2 p^{O}-1\right)} \frac{\Phi_{3}}{1+\rho \phi^{2}-(1+\rho) \phi\left(p^{O}\right)^{\sigma-1}}
$$

The shape of this function depends on the interaction of offshoring costs and trade costs. Figure 2 below plots $\Lambda$ in the three-dimensional space as a function of $\phi$ and $p^{O}$, for the symmetric case, $\rho=1 .^{12}$

Figure 2: How $\phi$ and $p^{O}$ affect $\Lambda$ in the interior equilibrium

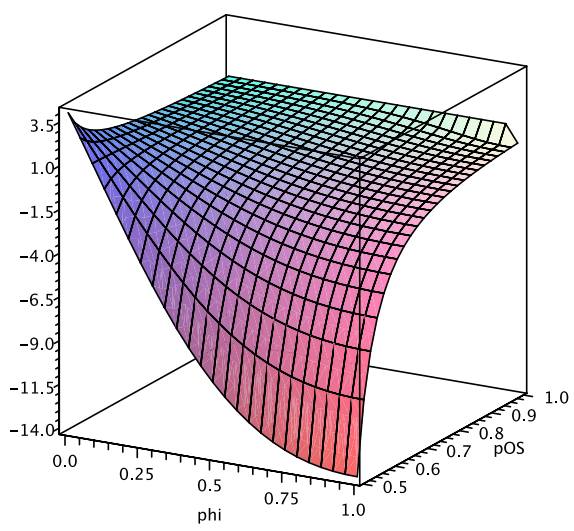

The impact of offshoring costs is in principle ambiguous. Recall that $n^{O}$ negatively depends on offshoring costs and $\lambda^{O}$ positively depends on them. As offshoring costs decrease - for given trade freeness - $n^{O}$ will increase, but $\lambda^{O}$ will decrease, so the overall effect on $\Lambda$ is not clear ex ante. This is seen in the Figure: $\Lambda$ rises with $p^{O}$ for sufficiently high $\phi$ and it decreases for sufficiently low $\phi$.

The impact of trade costs can in turn be signed:

$$
\left.\frac{\partial \Lambda}{\partial \phi}\right|_{\rho=1}=-\frac{\sigma p^{O}(1+\phi)(1-\phi)\left[\left(p^{O}\right)^{1-\sigma}-\left(p^{O}\right)^{\sigma-1}\right]}{\left[\sigma\left(2 p^{O}-1\right)+1-p\right]\left(1+\phi^{2}-2 \phi\left(p^{O}\right)^{\sigma-1}\right)^{2}}<0
$$

Since $\Lambda$ decreases everywhere in $\phi$, there is a unique level of trade freeness at which $\Lambda=1$, denoted $\bar{\phi}$. This threshold level is itself a decreasing function

\footnotetext{
${ }^{12}$ Recall that we use the collection of parameters $p^{O}$ as a measure of offshoring costs.
} 
of offshoring costs. ${ }^{13}$

This is clear in Figure 3, that plots $\Lambda$ (the bold curve) as a function of $p^{O}$ for increasing levels of $\phi$ from the left to the right panel.

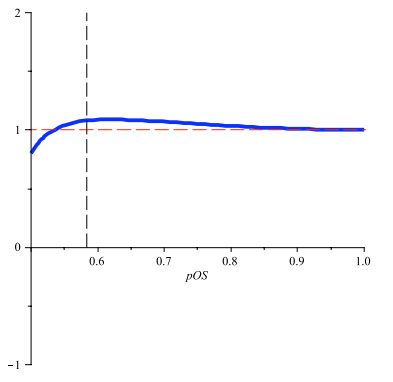

(a) $\phi=0.1$

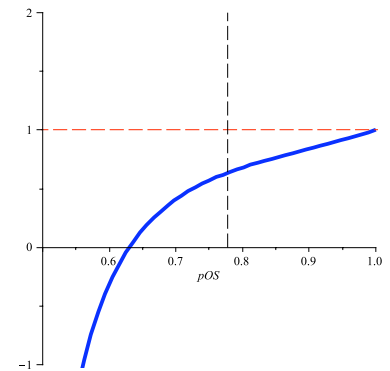

(b) $\phi=0.3$

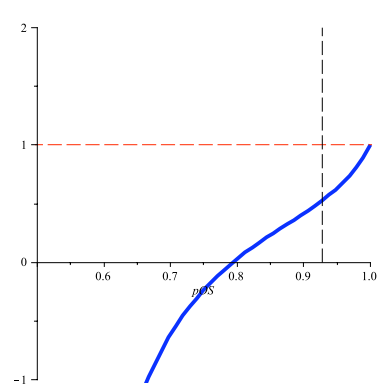

(c) $\phi=0.5$

Figure 3: $\Lambda$ in interior equilibrium

In each panel, the dotted vertical line represents the sustain level of $p^{O}$, $\left(p^{O}\right)^{S}$, which we found in Section 3.3 to be equal to $\left[\frac{\phi(1+\rho)}{\rho+\phi^{2}}\right]^{\frac{1}{\sigma-1}}$. Since we are at an interior equilibrium, only the part of the Figure to the right this line should be considered. As explained above, $\left(p^{O}\right)^{S}$ is increasing in $\phi . \Lambda$ is the solid line. If this line is below the horizontal dotted line, manufacturing Home labor demand increases, and viceversa.

In the left panel, the $\Lambda$ curve is downward-sloping: as offshoring costs decrease, the decrease in $\lambda^{O}$ more than offsets the increase in $n^{O}$. In the central and right panel the $\Lambda$ curve is upward-sloping: for higher levels of $\phi, n^{O}$ increases more than $\lambda^{O}$ decreases.

The main insight from Figures 2 and 3 is that when trade freeness is not too low, the $\Lambda$ function is below 1 . Hence:

Result 5. There is job loss only for low levels of trade freeness, while when trade is more free offshoring brings about an increase in manufacturing labor demand in the offshoring country.

As trade costs get reduced, it becomes more convenient to locate production in the Home market, so the demand for labor in manufacturing increases.

\footnotetext{
${ }^{13} \mathrm{~A}$ simple expression can be found imposing $\sigma=2$. The threshold level of $\phi$ then solves to $\bar{\phi}=1+2 p^{O}-2 \sqrt{p^{O}\left(1+p^{O}\right)}$, with $\frac{\partial \bar{\phi}}{\partial p^{O}}<0$.
} 


\section{Case 2 Core-periphery equilibrium}

If offshoring costs are low enough to cause a core-periphery outcome, the function $\Lambda$ will be unambiguously downward-sloping, because offshoring costs will only affect employment per firm $\lambda^{O}$, not the number of firms. The simple expression for $\Lambda$ is:

$$
\Lambda=\frac{\rho \sigma(1-\rho \phi) p^{O}}{(1+\rho)(1-\phi)\left[1-p^{O}+\sigma\left(2 p^{O}-1\right)\right]}
$$

If we impose equal effective size, $\rho=1, \Lambda$ will not depend on $\phi$ any longer:

$$
\left.\Lambda\right|_{\rho=1}=\frac{1}{2} \frac{\sigma p^{O}}{\left(1-p^{O}\right)+\sigma\left(2 p^{O}-1\right)}
$$

Hence, in the core-periphery case with equal effective size, trade freeness will not affect the shape of the $\Lambda$ curve, but only the level of $\left(p^{O}\right)^{S}$, thus the probability of being in an equilibrium with all manufacturing production in the offshoring country.

Figure 4 graphically represents the core-periphery $\Lambda$ schedule (in bold) of equation (4.3). It is downward-sloping, so it crosses the 1-line only once, at the point where manufacturing labor demand in not affected by offshoring. We can easily determine the level of $p^{O}$ such that $\Lambda=1$ to be equal to $\frac{2(\sigma-1)}{3 \sigma-2}$ (this is the vertical dashed line in Figure 4). For future reference, notice that this threshold is lower than $2 / 3$ for all acceptable values of $\sigma$.

Figure 4: $\Lambda$ in core-periphery equilibrium

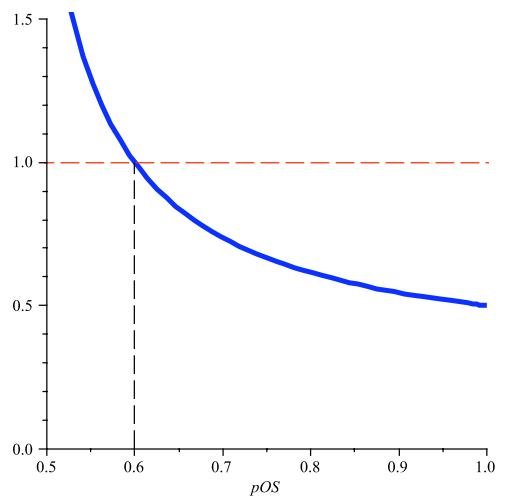

As the Figure clearly shows: 
Result 6. In a core-periphery equilibrium with equal effective size, the change in manufacturing labor demand only depends on the level of offshoring costs. Labor demand increases if they are high enough, and decreases otherwise.

The intuition is clear: Starting in core-periphery, as offshoring costs decrease, more and more firms will entry, with positive effects on labor demand. However, after a certain threshold, the offshoring of tasks to the low-wage nation will more than offset the increase in the number of firms, depressing manufacturing labor demand in the Home nation.

\section{Offshoring in a three-countries world}

In this section, we study a three-countries extension of the model presented above to analyze the extent of third-nation competitive effects (" us versus them effects").

We consider a world with two rich nations that can potentially offshore to one poor nation. We set up the model such that the equilibrium is qualitatively identical to that of Section 3 when both rich nations offshore. The focus of the analysis is on the effects of one rich nations forbidding offshoring.

We show that the "us versus them effects" is pervasive. The natural policy implication is that a country whose firms are competing in an international environment should not restrict offshoring.

\subsection{Initial equilibrium}

Consider a world of three countries. Two of them (country 1 and 2) are perfectly symmetric. The other country (country 3 ) is assumed to be technologically inferior to the other countries in both sectors:

$$
a_{k, 3}=\delta a_{k, 1}=\delta a_{k, 2} \quad \delta>1
$$

where $k \in(A, M)$. With the same assumptions and normalizations as before, we can derive the wage rates prevailing in each country as: $w_{1}=w_{2}=1$; $w_{3}=1 / \delta$. As in Section 3, we also assume that fixed costs are higher in country 3: $F_{3}=\delta F_{1}=\delta F_{2}$. For notational simplicity, we let $w_{1}=w_{2}=w$, $L_{1}=L_{2}=L, F_{1}=F_{2}=F$.

In this model, an equilibrium without offshoring is described by the following 
free-entry conditions:

$$
\begin{aligned}
& \pi_{1}=\frac{\mu}{\sigma}\left[\frac{E_{1}}{\Delta_{1}}+\phi\left(\frac{E_{2}}{\Delta_{2}}+\frac{E_{3}}{\Delta_{3}}\right)\right]=\frac{1}{\sigma} \\
& \pi_{2}=\frac{\mu}{\sigma}\left[\frac{E_{2}}{\Delta_{2}}+\phi\left(\frac{E_{1}}{\Delta_{1}}+\frac{E_{3}}{\Delta_{3}}\right)\right]=\frac{1}{\sigma} \\
& \pi_{3}=\frac{\mu}{\sigma}\left[\frac{E_{3}}{\Delta_{3}}+\phi\left(\frac{E_{1}}{\Delta_{1}}+\frac{E_{2}}{\Delta_{2}}\right)\right]=\frac{1}{\sigma}
\end{aligned}
$$

where

$$
\Delta_{1}=n_{1}+\phi\left(n_{2}+n_{3}\right) ; \quad \Delta_{2}=n_{2}+\phi\left(n_{2}+n_{3}\right) ; \quad \Delta_{3}=n_{3}+\phi\left(n_{1}+n_{2}\right)
$$

and the market size conditions:

$$
\begin{aligned}
& E_{1}=w L_{1}=L=w L_{2}=E_{2} \\
& E_{3}=w_{3} L_{3}=\frac{L_{3}}{\delta}
\end{aligned}
$$

We get the following solutions for the number of firms and the welfare levels:

$$
\begin{aligned}
n_{1} & =n_{2}=\frac{\mu\left(\delta L-\phi L_{3}\right)}{\delta(1-\phi)} \\
n_{3} & =\frac{\mu\left(L_{3}(1+\phi)-2 \phi \delta L\right)}{\delta(1-\phi)} \\
W_{1} & =W_{2}=(L)^{\gamma}[\mu(1+2 \phi)]^{\frac{\mu}{\sigma-1}} \\
W_{3} & =\left(\frac{L_{3}}{\delta}\right)^{\gamma}[\mu(1+2 \phi)]^{\frac{\mu}{\sigma-1}}
\end{aligned}
$$

In this case, too, there are some conditions under which a core-periphery equilibrium, with core in countries 1 and 2, emerge. The maximum level of trade freeness beyond which country 3 does not produce any manufacturing is equal to:

$$
\widetilde{\phi}^{S}=\frac{\frac{L_{3}}{\delta}}{\left(2 L-\frac{L_{3}}{\delta}\right)}=\frac{\widetilde{\rho}}{2-\widetilde{\rho}}
$$

where $\widetilde{\rho}$ is the effective size ratio between country 3 and any of the other countries: $\widetilde{\rho} \equiv \frac{L_{3} / \delta}{L}$. So $\widetilde{\phi}^{S}=1$ only if country 3 has the same effective size of any of the two other countries. If country 3 has a smaller effective size than $L$, for high enough $\phi$ there is a core-periphery equilibrium, with core 
is countries 1 and 2 .

The symmetric equilibrium with equal effective size is described by:

$$
\begin{aligned}
n_{j}^{s} & =\mu L \\
W_{j}^{s} & =(L)^{\gamma}[\mu(1+2 \phi)]^{\frac{\mu}{\sigma-1}}
\end{aligned}
$$

for $j=1,2,3$.

\subsection{Equilibrium under symmetric offshoring (OSS)}

Consider now the possibility of offshoring some tasks under task-specific offshoring costs. The most natural setting to consider is a symmetric one where both country-1 and country-2 firms offshore tasks in country 3 . Under symmetric offshoring, the model is equivalent to the two-countries model, because we can treat the two offshoring countries as a single country. As shown in Appendix A, the results in terms of number of active firms, welfare and manufacturing labor demand mimic the ones we discussed in the first specification of the model.

\subsection{Equilibrium under asymmetric offshoring (AOS)}

Let's consider the case in which country 1 allows its firms to offshore some tasks in country 3 , while country 2 imposes a ban on offshoring. ${ }^{14}$

The case of asymmetric offshoring can be represented by the following system of free-entry conditions:

$$
\begin{aligned}
& \pi_{1}=\frac{\mu}{\sigma}\left[\frac{\left(p^{O}\right)^{1-\sigma} L}{\Delta_{1}^{O}}+\phi\left(\frac{\left(p^{O}\right)^{1-\sigma} L}{\Delta_{2}^{O}}+\frac{\left(p^{O}\right)^{1-\sigma}\left(L_{3} / \delta\right)}{\Delta_{3}^{O}}\right)\right]=\frac{1}{\sigma} \\
& \pi_{2}=\frac{\mu}{\sigma}\left[\frac{L}{\Delta_{2}^{O}}+\phi\left(\frac{L}{\Delta_{1}^{O}}+\frac{\left(L_{3} / \delta\right)}{\Delta_{3}^{O}}\right)\right]=\frac{1}{\sigma} \\
& \pi_{3}=\frac{\mu}{\sigma}\left[\frac{L_{3} / \delta}{\Delta_{3}^{O}}+\phi\left(\frac{L}{\Delta_{1}^{O}}+\frac{L}{\Delta_{2}^{O}}\right)\right]=\frac{1}{\sigma}
\end{aligned}
$$

\footnotetext{
${ }^{14}$ This assumption is made for pedagogical purposes. However, the possibility that governments implement policies that limit the ability of domestic firms to offshore is real. For example, as reported by Spencer (2005), during the 2004 US election campaign there were suggestions that the US should tighten visa restrictions to limit the possibility of training foreign software engineers in preparation for offshoring.
} 
where

$$
\begin{aligned}
& \Delta_{1}^{O}=\left(p^{O}\right)^{1-\sigma} n_{1}^{O}+\phi\left(n_{2}^{O}+n_{3}^{O}\right) \\
& \Delta_{2}^{O}=n_{2}^{O}+\phi\left(\left(p^{O}\right)^{1-\sigma} n_{1}^{O}+n_{3}^{O}\right) \\
& \Delta_{3}^{O}=n_{3}^{O}+\phi\left(\left(p^{O}\right)^{1-\sigma} n_{1}^{O}+n_{2}^{O}\right)
\end{aligned}
$$

The analytical solution for the free-entry conditions is found by imposing particular values of the market size and technology parameters. Choosing the values $L=1 / 3 ; L^{*}=1 / 2 ; \delta=3 / 2$, which corresponds to the case $\widetilde{\rho}=1$, the system solves to:

$$
\begin{aligned}
n_{1}^{O} & =\frac{1}{3} \frac{\mu}{\Psi}\left[1+\phi(1+4 \phi)-3 \phi(1+\phi)\left(p^{O}\right)^{\sigma-1}\right] \\
n_{2}^{O} & =n_{3}^{O}=\frac{1}{3} \frac{\mu}{\Psi}\left[1+\phi(1+\phi)-3 \phi\left(p^{O}\right)^{1-\sigma}\right] \\
W_{1}^{O} & =\left(\frac{1}{3}\right)^{\gamma}\left[\frac{\mu}{\Psi}\left(\kappa_{1}\left(p^{O}\right)^{1-\sigma}-\kappa_{2}\left(p^{O}\right)^{2(1-\sigma)}+\kappa_{3}\right)\right]^{\frac{\mu}{\sigma-1}} \\
W_{2}^{O} & =\left(\frac{1}{3}\right)^{\gamma}\left[\frac{\mu}{\Psi}\left(\kappa_{4}\left(p^{O}\right)^{1-\sigma}-\kappa_{5}\left(p^{O}\right)^{2(1-\sigma)}+\kappa_{6}\right)\right]^{\frac{\mu}{\sigma-1}} \\
W_{3}^{O} & =\left(\frac{1}{3}\right)^{\gamma}\left[\frac{\mu}{\Psi}\left(\kappa_{7}\left(p^{O}\right)^{1-\sigma}-\kappa_{8}\left(p^{O}\right)^{2(1-\sigma)}+\kappa_{9}\right)\right]^{\frac{\mu}{\sigma-1}}
\end{aligned}
$$

where $\Psi \equiv 1+\phi(1+2 \phi)-\phi\left[2\left(p^{O}\right)^{1-\sigma}+(1+\phi)\left(p^{O}\right)^{\sigma-1}\right] ; \kappa_{1} \equiv 1+\phi^{3}+$ $2 \phi(1+\phi) ; \kappa_{2} \equiv 3 \phi^{2} \kappa_{3} \equiv \phi^{3}-2 \phi(1+\phi) ; \kappa_{4} \equiv 1-\phi^{2}+2 \phi\left(1+2 \phi^{2}\right)$; $\kappa_{5} \equiv \kappa_{2} / \phi ; \kappa_{6} \equiv \phi[1-2 \phi(1+\phi)] ; \kappa_{7} \equiv \phi\left(5 \phi^{2}+2 \phi-1\right) ; \kappa_{8} \equiv \kappa_{2} ; \kappa_{9} \equiv$ $1+\phi\left(1-2 \phi-3 \phi^{2}\right)$.

In this interior equilibrium country 2 becomes similar to country 3 in terms of number of manufacturing firms, because its firms do not have access to offshoring.

The welfare implications are easily described: country 1 has now a higher welfare than country 2 (this is intuitively clear and can be checked graphically): since country 1 firms have smaller costs of production than country 2 firms, more firms will be active in country 1, with positive cost-of-living effects on welfare.

This interior equilibrium is sustainable only for $p^{O}<\left(\widetilde{p}^{O}\right)^{S}=\left[\frac{3 \phi}{1+\phi(1+\phi)}\right]^{\frac{1}{\sigma-1}}$, which implies:

$$
\widetilde{\beta}^{S}=\frac{1}{2} \frac{\delta}{1-\left[\frac{3 \phi}{1+\phi(1+\phi)}\right]^{\frac{1}{\sigma-1}}}
$$


When offshoring costs are lower than this threshold, we have a core-periphery equilibrium, with core in country 1 and periphery in countries 2 and 3 . The equations for the number of firms and the levels of welfare characterizing this core-periphery equilibrium are:

$$
\begin{aligned}
n_{1}^{O} & =\mu\left(2 L+\frac{L_{3}}{\delta}\right) \\
n_{3}^{O} & =n_{2}^{O}=0 \\
W_{1}^{O} & =L\left[\mu\left(2 L+\frac{L_{3}}{\delta}\right)\left(p^{O}\right)^{1-\sigma}\right]^{\frac{\mu}{\sigma-1}} \\
W_{2}^{O} & =\phi^{\frac{\mu}{\sigma-1}} W_{1}^{O} \\
W_{3}^{O} & =\left(\frac{L_{3}}{\delta}\right)\left[\mu \phi\left(2 L+\frac{L_{3}}{\delta}\right)\left(p^{O}\right)^{1-\sigma}\right]^{\frac{\mu}{\sigma-1}}
\end{aligned}
$$

Country 2 loses the entire manufacturing sector (it becomes part of the global periphery). Moreover, all tasks are offshored to country 3: offshoring in country 2 would not be more convenient than keeping all the production in country 1.

For what concerns welfare, country 2 has a lower welfare than country 1 (which enjoys the highest welfare level because of cost-of-living effects), and welfare equal to country 3 's if $\widetilde{\rho}=1$. To summarize:

Result 7. Asymmetric offshoring drives a wedge, in terms of number of manufacturing firms and welfare, between the offshoring rich nation and the non-offshoring rich nation. If offshoring costs are low enough, the non-offshoring rich nation stops producing manufactured varieties and becomes part of the global periphery.

\subsection{Labor demand effects under asymmetric offshoring}

Manufacturing labor demand effects will be different for countries 1 and 2 in this case. We analyze them in turn.

\subsubsection{Country 1}

In an interior equilibrium (IE), the offshoring country generally experiences an increase in manufacturing labor demand, even under low trade freeness. This is shown in Figure 5 below. ${ }^{15}$

\footnotetext{
${ }^{15}$ The algebraic expression for $\Lambda$ is too complex and is thus omitted.
} 


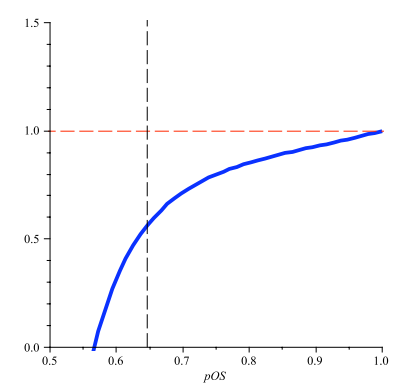

(a) $\phi=0.1$

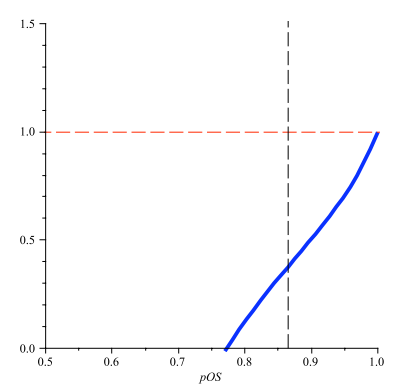

(b) $\phi=0.3$

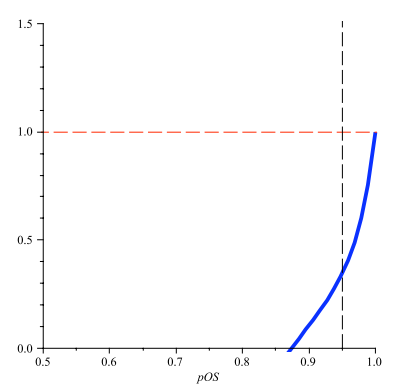

(c) $\phi=0.5$

Figure 5: $\Lambda$ in interior equilibrium, country 1, AOS

In a core-periphery equilibrium (CP), the $\Lambda$ schedule is simply expressed as:

$$
\widetilde{\Lambda}=\frac{\sigma(1-\widetilde{\rho} \sigma) p^{O}}{(1-\phi)(2+\widetilde{\rho})\left[1-p^{O}+\sigma\left(2 p^{O}-1\right)\right]}
$$

which is downward-sloping and intersects the 1-line only once. ${ }^{16}$ Under symmetry $(\widetilde{\rho}=1)$, this expression is independent of $\phi$ :

$$
\left.\widetilde{\Lambda}\right|_{\widetilde{\rho}=1}=\frac{1}{3} \frac{\sigma p^{O}}{1-p^{O}+\sigma\left(2 p^{O}-1\right)}
$$

The intersection between $\widetilde{\Lambda}$ and the 1-line gives the minimum value of $p^{O}$ such that manufacturing labor demand is positively affected by offshoring. If $\widetilde{\rho}=1$, it is equal to $\frac{3(\sigma-1)}{5 \sigma-3}$, which is lower that $3 / 5$ for any acceptable value of $\sigma$.

Recall that in the two-countries case this threshold was equal to $\frac{2(\sigma-1)}{3 \sigma-2}$, which is higher than $\frac{3(\sigma-1)}{5 \sigma-3}$ for all $\sigma$. In words, the range of offshoring costs for which manufacturing jobs are lost in the offshoring country is now smaller. Hence:

Result 8. The offshoring rich nation generally benefits from asymmetric offshoring in terms of number of jobs in the manufacturing sector in the interior equilibrium. In the core-periphery equilibrium where it produces all manufactures, this is true except when offshoring costs are very close to their lower bound.

\footnotetext{
${ }^{16}$ The shape of the $\Lambda$ schedule is the same as in Figure 4.
} 


\subsubsection{Country 2}

In a core-periphery equilibrium, we have seen that country 2 loses the entire manufacturing sector, hence manufacturing labor demand drops to zero.

If we stay in an interior equilibrium, the change in manufacturing labor demand is simply equal to the change in the number of firms, because country 2 is neither exporter or recipient of offshoring. Using the same notation as before, we can thus construct the "job loss" function $\Lambda$ as:

$$
\widetilde{\Lambda} \equiv \frac{n_{2}}{n_{2}^{O}}=\frac{\Psi}{1+\phi(1+\phi)-3 \phi\left(p^{O}\right)^{1-\sigma}}
$$

where $n_{2}^{O}$ is defined in (5.3). This function is everywhere above 1 in the relevant area $\left(p^{O}>\left(\widetilde{p}^{O}\right)^{S}\right) \cdot{ }^{17}$

Result 9. Under asymmetric offshoring, the non-offshoring rich nation unambiguously loses manufacturing jobs.

\section{Concluding remarks}

The progressive improvements in information and communication technologies have made it possible to disintegrate, or unbundle, the production processes of goods and services at great depth. Offshoring, or trade in tasks, is the latest development of this process.

This paper has contributed to the literature on the general equilibrium effects of offshoring with a particular emphasis on manufacturing employment. This is a hot issue in the policy debate about offshoring in the rich countries, and one that unfortunately is often plagued by misconceptions. The most fundamental misconception about labor demand effects of offshoring is the lump-of-labor fallacy (thinking that there is a fixed stock of labor to be filled, and once the stock has been exhausted, there is unemployment). This fallacious line of thinking leads to equate the number of jobs that are " offshorable" to the number of jobs that will be lost due to offshoring to low-wage countries.

In this paper, we make the basic point that offshoring is a source of comparative advantage, so it affects the location of industries. The assessment of the labor demand effects of offshoring must then consider not only the number of jobs (in our model, tasks) that cease to be done in the rich nation, but also the additional number of jobs created by firms that are more

\footnotetext{
${ }^{17}$ There is no job loss in country 2 only in the limiting case in which offshoring does not reduce costs, that is $\widetilde{\Lambda} \rightarrow 1$ if $p^{O} \rightarrow 1$.
} 
productive because of offshoring.

The first part of this paper has considered a simple 2-nations model where a more productive nation can offshore (at cost) some tasks of manufacturing production in the least productive nation. Starting from a symmetric equilibrium, offshoring puts Foreign firms at competitive disadvantage vis-à-vis domestic ones. If offshoring costs fall below a certain threshold, no more firms find it profitable to operate in Foreign, so that a core-periphery equilibrium with no firms abroad emerges.

The number of manufacturing workers is affected by offshoring via the number of firms (labor is the input of production) and the number of tasks offshored. We have shown that the overall number of firms increases, but employment per firm decreases, with opposite effects on manufacturing labor demand at Home. These effects depend on the interaction between offshoring costs and trade costs. If the former are not too low, an interior equilibrium with manufacturing production in both nations is sustained. In this case labor demand effects are positive, except when trade costs are really low.

If offshoring costs are low enough to yield a core-periphery equilibrium, on the other hand, labor demand effects only depend on offshoring costs: they are positive for high enough offshoring costs, and negative for lower offshoring costs. Intuitively, when offshoring costs are very low the set of offshored tasks is very large, so that the increase in the number of firms is not enough to compensate the loss of these tasks.

The important policy prescription we draw is that if a government is concerned about potential job loss because of offshoring, a more protectionist trade policy stance could prove to be a self-defeating strategy.

Insofar offshoring is a source of comparative advantage, it has third-country competitive effects. In the second part of the paper we have extended the model to three countries, two symmetric rich nations and a third nation which is a natural recipient of offshoring, to analyze the extent of "race to the bottom" effects. We have shown that these effects are pervasive: Under asymmetric offshoring, the offshoring country generally sees an increase in the number of manufacturing jobs. The non-offshoring country, on the other hand, by adopting a policy that reduces the ability of its firms to compete internationally (in this case, a full-fledged ban on offshoring), experiences a reduction in manufacturing labor demand. When the benefits of offshoring are high enough, the non-offshoring country may even lose the entire manufacturing sector and become part of the global periphery.

The policy implication is clear: the attempt to save jobs by adopting poli- 
cies that eventually reduce the capacity of firms to compete internationally would be misguided and self-defeating.

\section{References}

Amiti, M., and S.-J. Wei, 2005, "Fear of service outsourcing: is it justified?," Economic Policy, 20, 308-347.

Amiti, M., and S.-J. Wei, 2006, "Service Offshoring and Productivity: Evidence from the United States," NBER Working Paper 11926.

Ando, M., and F. Kimura, 2007, "Globalizing Corporate Activities and Their Domestic Impacts: Evidence from Japanese Firms," Keio University.

Baldwin, R. E., 2006a, "Globalisation: the great unbundling(s)," Paper for the Finnish Prime Minister's Office, Economic Council of Finland as part of EU Presidency.

Baldwin, R. E., 2006b, "Offshoring and globalisation: What is new about the new paradigm?," Graduate Institute of International Studies, Geneva.

Baldwin, R. E., R. Forslid, P. Martin, G. Ottaviano, and F. Robert-Nicoud, 2003, Economic Geography and Public Policy, Princeton University Press, Princetion, NJ.

Baldwin, R. E., and F. Robert-Nicoud, 2007, "Offshoring: General Equilibrium Effects on Wages, Production and Trade," NBER Working Paper 12991.

Blinder, A. S., 2005, "Fears of Offshoring," CEPS Working Paper 119, Princeton University, Princeton, NJ.

Blinder, A. S., 2007, "How Many U.S. Jobs Might Be Offshorable?," CEPS Working Paper 142, Princeton University, Princeton, NJ.

Crinò, R., 2007, "Offshoring, Multinationals and Labor Market: A Review of the Empirical Literature," CESPRI Working Paper 196, Università Bocconi, Milano, Italy.

Egger, H., and P. Hegger, 2001, "International Outsourcing and the Productivity of Low-skilled Labour in the EU," WIFO Working Paper 152. 
Egger, P., M. Pfaffermayr, and Y. Wolfmayr-Schnitzer, 2001, "The international fragmentation of Austrian manufacturing: The effects of outsourcing on productivity and wages," The North American Journal of Economics and Finance, 12, 257-272.

Ekholm, K., and K. Hakkala, 2005, "The Effect of Offshoring on Labor Demand: Evidence from Sweden," Working Paper 654, Research Institute of Industrial Economics.

Ekholm, K., and K.-E. Ulltveit-Moe, 2007, "A New Look at Offshoring and Inequality: Specialization Versus Competition," CEPR Discussion Paper 6402 .

Feenstra, R. C., and G. H. Hanson, 1996, "Globalization, Outsourcing, and Wage Inequality," The American Economic Review, 86, 240-245.

Feenstra, R. C., and G. H. Hanson, 1999, "The Impact of Outsourcing and High-Technology Capital on Wages: Estimates for the United States, 1979-1990," The Quarterly Journal of Economics, 114, 907-940.

Friedman, T. L., 2006, The World is Flat: The Globalized World in the Twenty-First Century, Penguin Books, London, UK.

Grossman, G. M., and E. Rossi-Hansberg, 2006, "Trading Tasks: A Simple Theory of Offshoring," NBER Working Paper 12721.

Hijzen, A., and P. Swamy, 2007, "Does Offshoring Reduce Industry Employment?," GEP Research Paper 2007/24, Luverhulme Centre, University of Nottingham, UK.

Hijzen, A., I. Tomojiko, and Y. Todo, 2007, "Does Offshoring Pay? FirmLevel Evidence From Japan," GEP Research Paper 2007/14, Luverhulme Centre, University of Nottingham, UK.

Kirkegaard, J. F., 2007, "Offshoring, Outsourcing, and Production Relocation-Labor-Market Effects in the OECD Countries and Developing Asia," Peterson Institute Working Paper WP07-02, Peterson Institute for International Economics.

Krugman, P., 1980, "Scale Economies, Product Differentiation, and the Pattern of Trade," The American Economic Review, 70, 950-959.

Mankiw, N. G., and P. Swagel, 2006, "The politics and economics of offshore outsourcing," Journal of Monetary Economics, 53, 1027-1056. 
McCarthy, J. C., 2002, "3.3 Million US Services Jobs To Go Offshore," Discussion paper, Forrester Research, Cambridge, MA.

Olsen, K. B., 2006, "Productivity Impacts of Offshoring and Outsourcing: A Review," OECD Science, Technology and Industry Working Paper 2006/1, OECD, Paris.

Spencer, B. J., 2005, "International Outsourcing and Incomplete Contracts," NBER Working Paper 11418.

Van Welsum, D., and X. Reif, 2005, "Potential Offshoring: Evidence from Selected OECD Countries," Discussion paper, Brookings Trade Forum.

Van Welsum, D., and G. Vickory, 2006, "The share of employment potentially affected by offshoring - an empirical investigation," Working party on the information economy report dsti/iccp/ie(2005)8, OECD, Paris.

\section{Appendix}

\section{A The results for 3 countries OSS}

In a three-country world with symmetric offshoring, the system of free-entry conditions is:

$$
\begin{aligned}
& \pi_{1}=\frac{\mu}{\sigma}\left[\frac{\left(p^{O}\right)^{1-\sigma} L}{\Delta_{1}^{O}}+\phi\left(\frac{\left(p^{O}\right)^{1-\sigma} L}{\Delta_{2}^{O}}+\frac{\left(p^{O}\right)^{1-\sigma}\left(L_{3} / \delta\right)}{\Delta_{3}^{O}}\right)\right]=\frac{1}{\sigma} \\
& \pi_{2}=\frac{\mu}{\sigma}\left[\frac{\left(p^{O}\right)^{1-\sigma} L}{\Delta_{2}^{O}}+\phi\left(\frac{\left(p^{O}\right)^{1-\sigma} L}{\Delta_{1}^{O S S}}+\frac{\left(p^{O}\right)^{1-\sigma}\left(L_{3} / \delta\right)}{\Delta_{3}^{O}}\right)\right]=\frac{1}{\sigma} \\
& \pi_{3}=\frac{\mu}{\sigma}\left[\frac{L_{3} / \delta}{\Delta_{3}^{O}}+\phi\left(\frac{L}{\Delta_{1}^{O}}+\frac{L}{\Delta_{2}^{O}}\right)\right]=\frac{1}{\sigma}
\end{aligned}
$$

where

$$
\begin{aligned}
& \Delta_{1}^{O}=\left(p^{O}\right)^{1-\sigma} n_{1}^{O}+\phi\left(\left(p^{O}\right)^{1-\sigma} n_{2}^{O}+n_{3}^{O}\right) \\
& \Delta_{2}^{O}=\left(p^{O}\right)^{1-\sigma} n_{2}^{O}+\phi\left(\left(p^{O}\right)^{1-\sigma} n_{1}^{O}+n_{3}^{O}\right) \\
& \Delta_{3}^{O}=n_{3}^{O}+\phi\left(p^{O}\right)^{1-\sigma}\left(n_{1}^{O}+n_{2}^{O}\right)
\end{aligned}
$$


The solutions - as a function of $p^{O}$ defined in (3.7) - are:

$$
\begin{aligned}
n_{1}^{O} & =n_{2}^{O}=\frac{\mu}{1-\phi}\left(\widetilde{\Phi}_{1} L-\widetilde{\Phi}_{2} \phi \frac{L_{3}}{\delta}\right) \frac{1}{\widetilde{\Phi}_{3}} \\
n_{3}^{O} & =\frac{\mu}{1-\phi}\left(\widetilde{\Phi}_{4} \frac{L_{3}}{\delta}-\widetilde{\Phi}_{5} \phi L\right) \frac{1}{\widetilde{\Phi}_{3}} \\
W_{1}^{O} & =W_{2}^{O}=W_{1}\left(\frac{\widetilde{\Phi}_{1}}{\widetilde{\Phi}_{6}}\right)^{\frac{\mu}{\sigma-1}} \\
W_{3}^{O} & =W_{3}\left(\frac{\widetilde{\Phi}_{2}}{\widetilde{\Phi}_{6}}\right)^{\frac{\mu}{\sigma-1}}
\end{aligned}
$$

where $\widetilde{\Phi}_{1} \equiv 1+\phi-2 \phi\left(p^{O}\right)^{\sigma-1} ; \widetilde{\Phi}_{2} \equiv \Phi_{2}$ defined in section 3.3;

$\widetilde{\Phi}_{3} \equiv \frac{1+\phi(1+2 \phi)-\phi\left[2\left(p^{O}\right)^{\sigma-1}+(1+\phi)\left(p^{O}\right)^{1-\sigma}\right]}{1-\phi} ; \widetilde{\Phi}_{4} \equiv(1+\phi)\left(1-\phi\left(p^{O}\right)^{1-\sigma}\right)$;

$\widetilde{\Phi}_{5} \equiv 2(1+\phi)\left(p^{O}\right)^{1-\sigma}-4 \phi ; \widetilde{\Phi}_{6} \equiv \frac{\left(p^{O}\right)^{\sigma-1}(1+\phi(1+2 \phi))-\phi\left(1+\phi+2\left(p^{O}\right)^{2(\sigma-1)}\right)}{1-\phi} ;$

$W_{1}$ and $W_{3}$ are respectively defined in (5.1) and (5.2).

Notice that the no-offshoring situation is a particular case of offshoring, with $p^{O}=p=1$.

In analogy with the two countries case, two cases need to be distinguished, an interior equilibrium where country 3 keeps producing manufacturing, and that is characterized by the above equations, and a core-periphery outcome where manufacturing production is done only in countries 1 and 2 . The level of $p^{O}$ below which the interior equilibrium computed above is not sustainable is equal to $\left[\frac{\phi(1+\phi)(2+\widetilde{\rho})}{\widetilde{\rho}(1+\phi)+4 \phi^{2}}\right]^{\frac{1}{\sigma-1}}$, which implies the following threshold level of offshoring costs:

$$
\widetilde{\beta}^{S}=\frac{1}{2} \frac{\delta}{1-\left[\frac{\phi(1+\phi)(2+\widetilde{\rho})}{\widetilde{\rho}(1+\phi)+4 \phi^{2}}\right]^{\frac{1}{\sigma-1}}}
$$

In a core-periphery equilibrium, we have:

$$
\begin{aligned}
n_{1}^{O} & =n_{2}^{O}=\frac{1}{2} \mu\left(2 L+\frac{L_{3}}{\delta}\right) \\
n_{3}^{O} & =0 \\
W_{1}^{O} & =W_{2}^{O}=L\left[\frac{1}{2} \mu(1+\phi)\left(L_{3}+2 \delta L\right)\left(p^{O}\right)^{1-\sigma}\right]^{\frac{\mu}{\sigma-1}} \\
W_{3}^{O} & =\left(\frac{L_{3}}{\delta}\right)\left[\mu \phi\left(L_{3}+2 \delta L\right)\left(p^{O}\right)^{1-\sigma}\right]^{\frac{\mu}{\sigma-1}}
\end{aligned}
$$


We can immediately see that, as in the 2-countries case, $n_{1}^{O}=n_{2}^{O}$ in coreperiphery does not depend on $p^{O}$; moreover, $W_{3}^{O}<W_{j}^{O}, j=1,2$ even if countries have equal effective size, $\widetilde{\rho}=1$ :

$$
\begin{array}{ll}
\frac{W_{j}^{O}}{W_{3}^{O}}=\left(\frac{\widetilde{\Phi}_{1}}{\widetilde{\Phi}_{2}}\right)^{\frac{\mu}{\sigma-1}}>1 & \text { in IE } \\
\frac{W_{j}^{O}}{W_{3}^{O}}=\left(\frac{1}{2} \frac{1+\phi}{\phi}\right)^{\frac{\mu}{\sigma-1}}>1 & \text { in } \mathrm{CP}
\end{array}
$$

\section{A.1 Labor demand effects}

As discussed in Section 4, the change in manufacturing labor demand following offshoring is equal to:

$$
\widetilde{\Lambda}_{j}=\frac{L_{M, j}}{L_{M, j}^{O}}=\frac{\lambda}{\lambda^{O}} \frac{n_{j}}{n_{j}^{O}} \quad j=1,2
$$

In the interior equilibrium, the expression for $\Lambda$ is:

$$
\widetilde{\Lambda}_{j}=\frac{(1-\widetilde{\rho} \phi) \sigma p^{O}}{\left[1-p^{O}+\sigma\left(2 p^{O}-1\right)\right]} \frac{\widetilde{\Phi}_{3}}{1+\phi(1+\widetilde{\rho} \phi)-\phi(2+\widetilde{\rho})\left(p^{O}\right)^{\sigma-1}}
$$

Figure 6 plots this function against $\phi$ and $p^{O}$. It is immediately clear that it has the same behavior as $\Lambda$ is the interior equilibrium with two countries (cfr. Figure 2). There is job loss in country $j, j=1,2$, only for low levels of trade freeness, while when trade is more free, offshoring raises manufacturing labor demand.

Figure 6: How $\phi$ and $p^{O}$ affect $\Lambda$ in the interior equilibrium

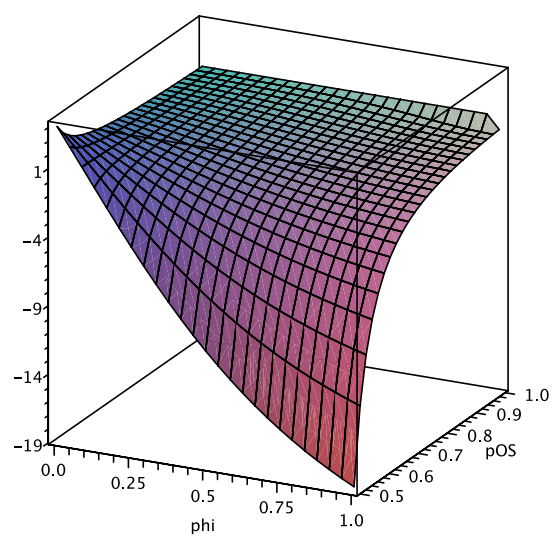


In the core-periphery equilibrium with core in countries 1 and 2 , the expression for $\Lambda$ is:

$$
\widetilde{\Lambda}_{j}=\frac{2(1-\widetilde{\rho} \phi) \sigma p^{O}}{(2+\widetilde{\rho})(1-\phi)\left[1-p^{O}+\sigma\left(2 p^{O}-1\right)\right]}
$$

If $\widetilde{\rho}=1$, this expression is independent of $\phi$. We can the find the level of $p^{O}$ such that $\widetilde{\Lambda}=1$ to be equal to $\frac{3(\sigma-1)}{4 \sigma-3}$, which is lower than $3 / 4 .{ }^{18}$ Offshoring raises manufacturing labor demand if offshoring costs are high enough, and depresses it if offshoring costs are low enough.

These results establish a qualitative similarity between the two countries model and the three-countries model with symmetric offshoring.

\footnotetext{
${ }^{18}$ In the two-countries model, this value was find to be lower than $2 / 3$. In the threecountries model the range of offshoring costs that depress manufacturing labor demand in core-periphery is thus larger than in the two-countries model.
} 